\title{
PENETAPAN DISPENSASI KAWIN AKIBAT HAMIL PRA-NIKAH DITINJAU DARI ASPEK MAQASHID SYARI'AH
}

\author{
Rizkiyah Hasanah \\ Hakim Pengadilan Agama Jember \\ e-mail: rizkihasanah@gmail.com
}

\begin{abstract}
Abstrak-Akhir-akhir ini angka pengajuan permohonan dispensasi kawin di Pengadilan Agama Banyuwangi cukup tinggi dan dalam kurun waktu enam tahun (2008-2013) ratarata $40 \%$ perkara dispensasi kawin yang masuk adalah akibat hamil pra-nikah. Penelitian ini bertujuan untuk mengetahui pertimbangan hakim dalam menetapkan dispensasi kawin akibat hamil pra-nikah dan untuk memahami aspek maqashid syari'ah Islam terhadap penetapan hakim tersebut. Metode penelitian ini menggunakan pendekatan yuridis normatif dan bersifat deskriptif analistis. Dari hasil penelitian menunjukkan bahwa Hakim Pengadilan Agama Banyuwangi dalam menetapkan dispensasi kawin akibat hamil pra-nikah berdasarkan pertimbangan hukum yuridis (berdasarkan aturan perundangan yang berlaku), berdasarkan pertimbangan hukum Islam dan berdasarkan pertimbangan keadilan masyarakat. Penetapan hakim tersebut ditinjau dari aspek maqashid syari'ah Islam dari segi kemaslahatannya adalah lebih mengutamakan hifz al-nasl, sedangkan dari segi mafsadatnya hifz al-din tidak tercapai yaitu terjadi pelanggaran syari'at Islam tentang larangan zina dengan menjadikan KHI Pasal 53 sebagai legalitas kawin hamil akibat zina.
\end{abstract}

Kata Kunci: Penetapan Hakim, Dispensasi Kawin, Hamil Pra-Nikah, Maqashid Syari'ah.

\begin{abstract}
The sum of dispensation of married submission in religion court Banyuwangi is high enough, and in six years period (2008-2013), about $40 \%$ cases about dispensation of married happened because of pregnancy before marriage. The purpose of this research is to analyze the opinion of the judges' consideration about dispensation of married because of pregnancy before marriage and also to explain the aspect of maqashid syari'ah Islam about the opinion of the judge. The method of the research uses juridical normative approach and descriptive analyze. From the result of the research, it indicates that the judge of religion court Banyuwangi decide the dispensation of married because of pregnancy before marriage based on the opinion of juridical law (according to the established law), according to the Islam law and according to the society's jurisdiction. The decision of the judge is overviewed from the aspect of maqashid syari'ah Islam, from the benefit aspect is given priority to hifz al-nasl. Meanwhile from mafsadat hifz al-din is not fullfilled, so that it becomes the violation of Islam law about the breach of any sexual act outside of marriage by being part of KHI section 53 as the legality of married because of pregnancy before marriage caused by any sexual act outside of marriage.
\end{abstract}

Keywords: The Opinion of Judge, Dispensation of Married, Pregnancy, Maqashid Syari'ah.

A. PENDAHULUAN

Tujuan pernikahan baik

menurut hukum positif yaitu menurut 
Rizkiyah Hasanah, Penetapan Dispensasi Kawin Akibat Hamil Pra-Nikah Ditinjau Dari Aspek ....

Pasal 1 Undang-Undang Nomor 1

Tahun 1974 maupun menurut hukum Islam yaitu Al-Qur'an dan Hadis, dan juga menurut Kompilasi Hukum Islam (KHI) pada Pasal 2 dan Pasal 3 pada intinya adalah mewujudkan kebahagiaan spiritual dan material serta kesejahteraan lahir batin di dunia dan akhirat. Tujuan perkawinan akan dapat segera tercapai jika kedua calon mempelai telah memenuhi usia kawin (matang jiwa raganya).

$$
\text { Pasal } 7 \text { ayat (1) Undang- }
$$

Undang Nomor 1 Tahun 1974 tentang Perkawinan, menyebutkan bahwa:

"Perkawinan hanya diizinkan jika pihak pria sudah mencapai umur 19 (sembilan belas) tahun dan pihak wanita sudah mencapai umur 16 (enam belas) tahun".

\section{Selanjutnya Undang-Undang} Nomor 1 Tahun 1974 tentang Perkawinan, menyebutkan bahwa:

"Dalam hal penyimpangan terhadap ayat (1) pasal ini dapat meminta dispensasi kepada Pengadilan atau Pejabat lain yang ditunjuk oleh kedua orang tua pihak pria maupun pihak wanita".

Dalam kehidupan sosial sekarang ini banyak kasus berkembang di tengah masyarakat yaitu tentang masalah kehamilan pra- nikah akibat zina. Permasalahan kawin hamil akibat zina merupakan permasalahan yang termasuk dalam wilayah khilafiyah.

Jumhur ulama' kebanyakan membolehkan mengawini wanita hamil seperti pendapat Imam $\mathrm{Abu}$ Hanifah, Syafi'i, Ibnu Hazm dari kelompok Adz Dzahiri, dll, sedangkan Imam Ahmad bin Hambal dan Imam Maliki melarangnya. Imam Malik dan Imam Ahmad bin Hambal mendasarkan larangannya pada maksud lahir ayat-ayat dan hadisthadist yang melarang membuahi janin yang sudah ada dari hubungan si wanita dengan orang lain.

Abu Hanifah dan Ibnu Hazm walaupun membolehkan perkawinannya, namun mereka melarang persenggamaan antara suami isteri tersebut sampai si wanita melahirkan anaknya. As Syafi'i membolehkan persenggamaan mereka karena tujuan nikah adalah menghalalkan persenggamaan. Dari ikhtilaf ini Imam Nawawi (dari madzhab Syafi'i) menyatakan: Hukum persenggamaan itu makruh (sampai sang bayi lahir), berdasarkan kaidah: "Al Khuruj minal ikhtilaaf 
Rizkiyah Hasanah, Penetapan Dispensasi Kawin Akibat Hamil Pra-Nikah Ditinjau Dari Aspek ....

Mustahab" (keluar dari perbedaan pendapat itu sangat dianjurkan) (Thursday, 2010).

Kompilasi Hukum Islam telah menetapkan keabsahan pernikahan antara seorang laki-laki dengan wanita yang hamil zina, dan menuangkannya pada BAB VIII Pasal 53, yaitu:

1) Seorang wanita hamil di luar nikah bisa dikawinkan dengan pria yang menghamilinya.

2) Perkawinan dengan wanita hamil yang disebut pada ayat (1) dapat dilangsungkan tanpa menunggu lebih dahulu kelahiran anaknya.

3) Dengan dilangsungkannya perkawinan pada saat wanita hamil, tidak diperlukan perkawinan ulang setelah anak yang dikandung lahir.

Adapun anak hasil hubungan zina, setelah perkawinan orang tuanya dapat ditetapkan:

1. Bila anak tersebut lahir 6 (enam) bulan lebih setelah perkawinan sah kedua orang tuanya, maka nasabnya adalah kepada suami yang telah mengawini ibunya itu.

2. Bila anak tersebut lahir kurang 6 (enam) bulan setelah perkawinan sah kedua orang tuanya, maka nasab anak tersebut adalah kepada ibunya.

Hal ini bersesuaian dengan pendapat jumhur ulama', diantaranya
Syekh Muhammad Zaid Al-Abyani yang menyatakan bahwa batas minimal umur kandungan adalah 180 hari sama dengan 6 bulan. Para Ulama' mendasarkan hukumnya dari perpaduan dua ayat, masing-masing dari Surat Al Ahqaf ayat 15 dan Surat Luqman ayat 14.

Menurut Surat Al-Ahqaf ayat 15 bahwa, waktu mengandung dan menyapih adalah 30 bulan. Menurut Luqman ayat 14 bahwa, waktu menyapih itu 24 bulan, jadi waktu hamil minimal 6 bulan. Imam Abu Hanifah menghitung jumlah 180 hari itu dari pernikahan, bukan dari mulainya hubungan seksual diantara kedua orang tua biologisnya (Thursday, 2010).

Pada kasus kedua yakni jika si anak lahir kurang dari 6 bulan, bila si anak terlahir perempuan jika ia hendak menikah, maka walinya bukan suami ibunya, namun wali hakim dan tentu saja anak tersebut secara syar' $i$ tidak mendapatkan hak waris sebagai anak sah dari suami ibunya itu bila nanti suami ibunya meninggal dunia dan meninggalkan harta warisan, kecuali bila yang meninggal dunia itu sebelumnya telah 
Rizkiyah Hasanah, Penetapan Dispensasi Kawin Akibat Hamil Pra-Nikah Ditinjau Dari Aspek ....

ikrar (membuat pernyataan) bahwa anak tersebut diakui sebagai anaknya sebagaimana diterangkan oleh Badran Abu Al-Ainain sebagai konsekwensi kebalikan pada kasus anak li'an (suami yang menuduh isterinya mengandung bukan dari dirinya). Namun demikian, ada beberapa pandangan tentang hal ini yang mengacu dari beberapa kasus persengketaan anak.

Seperti kasus persengketaan antara Sa'ad bin Abi Waqosh dan Abdu bin Zam'ah atau seperti apa yang diputuskan Umar bin Khottob tentang anak-anak jahiliyah yang terlahir dari kebiasaan wanita-wanita yang kumpul kebo dengan banyak lelaki, di mana Nabi dan Umar bin Khottob memutuskan bahwa anak tersebut (tanpa melihat umur kehamilan) adalah anak suaminya yang sah sesuai sabda Rasul dalam suatu peristiwa dalam riwayat yang panjang, di antaranya:

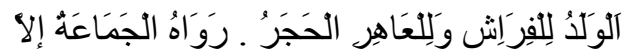

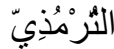

Artinya: "Anak itu dinasabkan kepada suami ibunya, sedangkan bagi si pelaku zina dia harus dihukum (dirajam)", Hadis riwayat Jama'ah ahli hadis terkecuali

Turmudzi,

Wallahu A'lam.

Belum selesai pembahasan tentang kontroversi hukum pernikahan dengan wanita hamil akibat zina, akhir-akhir ini justeru muncul problematika baru yaitu tentang masalah kehamilan pra-nikah akibat zina yang dilakukan oleh anakanak dan remaja yang masih berusia dini.

Praktik seks bebas dewasa ini tak bisa lagi dipungkiri. Kementerian Kesehatan pada tahun 2009 pernah merilis perilaku seks bebas remaja dari hasil penelitian di empat kota, yaitu Jakarta Pusat, Medan, Bandung, dan Surabaya. Hasilnya adalah sebanyak $35,9 \%$ remaja memiliki teman yang sudah pernah melakukan hubungan seksual sebelum menikah, bahkan $6,9 \%$ responden telah melakukan hubungan seksual sebelum menikah

\section{(www.kebijakankesehatanindonesi} a.net, 2013).

Data lain dari Riset Kesehatan Dasar (Riskesdas) 2010 Jakarta menunjukkan sebanyak $4,8 \%$ dari usia 10 tahun sampai 14 tahun telah melakukan hubungan di luar nikah. 
Rizkiyah Hasanah, Penetapan Dispensasi Kawin Akibat Hamil Pra-Nikah Ditinjau Dari Aspek ....

Sebesar $\quad 0,5 \%$ sampai $1,5 \%$ di antaranya hamil. Selain itu, sebesar 41,8\% pada usia 15 tahun sampai 19 tahun melakukan hubungan di luar nikah dan $13 \%$ di antaranya hamil (www.adminbaitulhikmah.com, 2013).

Adapun data dari Penelitian Survei Cepat Perilaku Remaja Januari-Februari 2014 Dinas Kesehatan Kabupaten Banyuwangi menemukan sebanyak $37,39 \%$ remaja telah melihat film $\mathrm{BF}$, sebanyak 7,53 persen telah saling rangsang, sebesar $20,82 \%$ telah melakukan masturbasi/onani, dan sebesar 3,90\% telah melakukan hubungan seks di luar nikah.

Pengadilan Agama Banyuwangi sebagai salah satu satuan kerja dari 37 (tiga puluh tujuh) Pengadilan Agama di Lingkungan Pengadilan Tinggi Agama Surabaya dalam Provinsi Jawa Timur termasuk Pengadilan Agama yang menerima perkara dengan volume besar di Jawa Timur yang sejak tahun 2011-2013 menduduki peringkat tiga besar.

Peningkatan pengajuan permohonan dispensasi kawin di Pengadilan Agama Banyuwangi dari tahun ke tahun semakin meningkat tajam dan drastis, khususnya antara tahun 2008-2013. Tahun 2008: 22 perkara. Tahun 2009: 24 perkara. Tahun 2010: 70 perkara. Tahun 2011: 165 perkara. Tahun 2012: 267 perkara. Dan tahun 2013: 357 perkara. Dalam kurun waktu enam tahun tersebut rata-rata $40 \%$ perkara yang masuk disebabkan karena hamil pra-nikah (Pengadilan Negeri Banyuwangi, 2013).

Setiap ketentuan hukum ataupun peraturan pasti memiliki tujuan yang dalam agama Islam disebut maqashid syari'ah. Tujuan disyari'atkan hukum adalah untuk memelihara kemaslahatan manusia dan sekaligus untuk menghindari mafsadah baik di dunia maupun di akhirat. Dalam rangka menjaga dan mewujudkan kemaslahatan tersebut menurut para ahli Ushul Fiqh ada lima unsur pokok yang harus dipelihara yaitu pemeliharaan agama (hifz al-din), jiwa (hifz al-nafs), akal (hifz al-aql), keturunan (hifz al-nasl), dan harta (hifz al-mal). Terkait dengan penerapan hukum, maka kelima unsur pokok itu dibedakan 
Rizkiyah Hasanah, Penetapan Dispensasi Kawin Akibat Hamil Pra-Nikah Ditinjau Dari Aspek ....

lagi menjadi tiga tingkat, yaitu: dharuriyyat, hajiyyat, tahsiniyyat.

Apabila kelima unsur pokok di atas dikaitkan dengan kasus dispensasi kawin akibat hamil pranikah, maka dalam hal penetapan hukum, pemeliharaan kelima unsur pokok di atas harus sesuai dengan situasi dan kondisi fakta hukum.

\section{B. HASIL DAN PEMBAHASAN}

1. Pertimbangan

Pengadilan

Banyuwangi

Menetapkan

Dispensasi

Kawin Akibat Hamil Pra-

Nikah

Sebanyak $\pm 40 \% \quad$ perkara dispensasi kawin yang masuk di Pengadilan Agama Banyuwangi antara tahun 2008 sampai tahun 2013 disebabkan hamil pra-nikah dan dari keseluruhan perkara dispensasi kawin yang masuk selama enam tahun tersebut $99 \%$ dikabulkan oleh Hakim Pengadilan Agama Banyuwangi.

Pertimbangan

Hakim

Pengadilan Agama Banyuwangi mengabulkan permohonan dispensasi kawin khususnya yang disebabkan hamil pra-nikah adalah: a. Pertimbangan yuridis (aturan perundang-undangan) yang berhubungan dengan perkara ini, antara lain:

1) Pasal 7 ayat (2) Undang-undang Nomor 1 Tahun 1974 tentang kebolehan mengajukan dispensasi kawin bagi calon mempelai yang umurnya tidak cukup sesuai Pasal 7 ayat (1) Undang-undang Perkawinan tersebut.

2) Pasal 53 Kompilasi Hukum Islam tentang kawin hamil.

3) Pasal 8, 9, 10, Undang-undang Nomor 1 tahun 1974 tentang Perkawinan jo Pasal 39-44 Kompilasi Hukum Islam yang menyebutkan tentang larangan kawin.

4) Pasal 16 dan 17 Kompilasi Hukum Islam yang menyebutkan tentang perkawinan yang didasarkan atas persetujuan calon mempelai.

b. Pertimbangan hukum Islam

Pertimbangan hakim adalah kaidah dalam hukum Islam yang berbunyi:

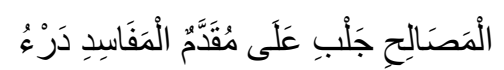

Artinya: "Menolak segala yang merusak harus didahulukan atas menarik segala yang bermaslahat".

c. Pertimbangan keadilan masyarakat 
Pernikahan merupakan solusi alternatif bagi penyelesaian masalah sosial yang akan terjadi yaitu untuk melindungi perempuan yang hamil tanpa suami dan anak yang dilahirkan di luar pernikahan yang sah, sehingga aspek keadilan masyarakat terpenuhi.

Ketentuan Pasal 7 ayat (2) Undang-undang Perkawinan serta Pasal 53 Kompilasi Hukum Islam dinilai longgar dan cenderung kompromistis karena tidak memberikan sanksi atau hukuman bagi pezina dan pelaku kawin usia dini, padahal dalam fiqih telah dijelaskan diantaranya: jika pelaku zina itu sudah menikah (zina muhsan) hukumannya adalah didera seratus kali dan kemudian dirajam dan bagi pelaku zina yang belum menikah (zina ghairu muhsan) hukumannya adalah didera seratus kali dan kemudian diasingkan ke tempat lain selama satu tahun (Asy-Syaukani, 1994:550). Kendati demikian, hakim menjatuhkan penetapan berdasarkan ketentuan Pasal 7 ayat (2) UndangUndang Perkawinan dan Pasal 53 KHI tersebut juga berpegangan pada alasan logis dan bisa dijadikan landasan hukum.

Jumhur fuqaha' membolehkan dan mengesahkan pernikahan dini bahkan lebih jauh lagi membolehkan pernikahan anak-anak. Dalam hal ini Ibnu al-Mundzir seperti dikutip oleh Ibnu Qudamah al-Maqdisi menyatakan:

"Ibnu al-Mundzir berkata:
semua orang yang kami anggap
ahli ilmu telah sepakat, bahwa
seorang ayah menikahkan anak
gadisnya yang masih kecil
hukumnya jaiz (boleh), jika ia
menikahkannya dengan pria
yang sekufu, dan boleh baginya
menikahkannya walau ia tidak
suka dan menolaknya (dengan
tanpa persetujuannya)" (Ibnu
Qudamah al-Maqdisyi:428).

Landasan normatif-teologis yang menjadi dasar pembolehan pernikahan anak-anak:

a. Surat At-Thalaq ayat 4: “...masa iddah mereka adalah tiga bulan, dan begitu (pula) perempuanperempuan yang tidak haid..." (Mujamma' Al Malik Fahd Li Thiba' Al Mushaf As Syarif Madinah Munawarah, 1971:946).

b. Surat An-Nur ayat 32: “...dan kawinkanlah orang-orang yang 
sedirian di antara kamu..." (Mujamma' Al Malik Fahd Li Thiba' Al Mushaf As Syarif Madinah Munawarah, 1971:549).

c. Hadis Bukhari, Muslim, Abu Dawud, Nasa $i$, dan Baihaqi:

"Khadijah wafat sebelum Nabi SAW hijrah ke Madinah 3 tahun sebelumnya, maka beliau tinggal di Madinah selama dua tahun atau sekitar itu. Dan nabi menikahi 'Aisyah tatkala berumur 6 tahun kemudian membina rumah tangga tatkala ia telah berusia 9 tahun" (Al-Bukhari, 284).

d. Perbuatan Sahabat

Menurut penuturan Ibnu Qudamah bahwasanya Qudamah bin Mazh'un menikahi anak perempuan Zubair ketika masih kecil, terus dikatakan kepadanya, maka ia menjawab, "anak perempuan Zubair jika aku mati ia mewarisiku, jika aku hidup maka ia adalah istriku". Imam Ali Karramallahu wajhah menikahkan putrinya Ummi Kultsum ketika masih kecil dengan Umar bin alKhattab (Ibnu Qudamah alMaqdisyi:428).

\section{Landasan} kebolehan melangsungkan perkawinan bagi wanita hamil menurut ketentuan Pasal 53 KHI secara tegas dibatasi pada perkawinan dengan laki-laki yang menghamilinya tersebut berdasarkan firman Allah SWT Surat An Nur ayat 3, yaitu:

\section{"Laki-laki yang berzina tidak mengawini melainkan perempuan yang berzina, atau perempuan yang musyrik; dan perempuan yang berzina tidak dikawini melainkan oleh laki- laki yang berzina atau laki-laki musyrik, dan yang demikian itu diharamkan atas orang-orang yang mukmin" (Mujamma' Al Malik Fahd Li Thiba' Al Mushaf As Syarif Madinah Munawarah, 1971:946).}

Hadis riwayat Aisyah, yaitu ketika Rasulullah SAW ditanya tentang seorang laki-laki yang berzina dengan seorang wanita, lalu laki-laki itu berniat mengawininya. Saat itu Rasululllah SAW menjawab:

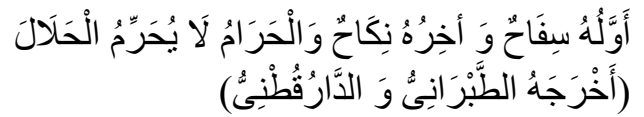

Artinya: "Permulaannya perzinaan, tetapi akhirnya adalah pernikahan (perkawinan). Dan yang haram itu tidak mengharamkan yang halal" (HR. Al-Thabraniy dan alDaruquthniy) (Zakiah Daradjat, 1995:113).

Selain itu, peristiwa yang diriwayatkan Ibnu Umar yaitu ketika 
Rizkiyah Hasanah, Penetapan Dispensasi Kawin Akibat Hamil Pra-Nikah Ditinjau Dari Aspek ....

Abu Bakar al-Shiddiq sedang di masjid, tiba-tiba datang seorang lakilaki dan berbicara tidak jelas serta tampak kebingungan. Kemudian Abu Bakar menyuruh Umar untuk mendatangi dan melihat laki-laki itu, dan ketika Umar mendapatkan jawaban bahwa laki-laki itu mempunyai seorang tamu, lalu tamunya itu berzina dengan anak perempuannya. Seketika itu Umar langsung memukul laki-laki itu dan berkata:

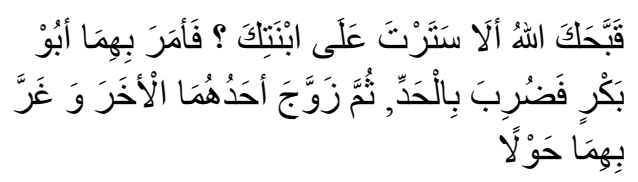

Artinya: "Jelek sekali engkau ini. Kenapa tidak engkau tutupi, tidak engkau rahasiakan saja hal anakmu itu? Abu Bakar lalu memerintahkan agar laki-laki yang berzina dan anak perempuan itu dihukum had. Kemudian Abu Bakar mengawinkan keduanya, lalu mengasingkan keduanya setahun" (Al-“Arabi, 262).

Namun demikian tidak semua perempuan boleh dinikahi, perempuan yang boleh dikawin hendaklah dia bukan orang yang haram bagi laki-laki yang akan mengawininya. Sebab-sebab haram selamanya ada tiga, yaitu nasab, mushaharah dan penyusuan (Sayyid Sabiq, 1980:103):

a. Haram karena nasab (keturunan), mereka adalah ibu kandung, anak perempuan kandung, saudara perempuan kandung, bibi dari garis ayah, bibi dari garis ibu, anak perempuan saudara laki-laki, anak perempuan saudara perempuan.

b. Haram karena mushaharah (perkawinan), mereka adalah Ibu dari isteri, anak tiri, isteri dari anak (menantu), isteri dari ayah (ibu tiri).

c. Haram karena penyusuan, mereka adalah ibu susu, nenek susu, bibi susu dari saudara perempuan ibu susu, saudara perempuan bapak susu, cucu perempuan ibu susu, saudara perempuan sesusuan, baik yang sebapak atau seibu atau sekandung.

Selain pertimbangan di atas, Pasal 7 ayat (2) Undang-undang Perkawinan serta Pasal 53 Kompilasi Hukum Islam memiliki landasan filosofis, sosiologis dan psikologis.

Analisis filosofisnya adalah untuk melindungi kelangsungan hidup wanita hamil di luar nikah, sekaligus menjaga kelangsungan hidup anaknya, analisis sosiologisnya adalah ketentuan pasal tersebut bisa dikatakan mengadopsi penyelesaian dalam masyarakat. Sistem adopsi tersebut merupakan hasil interaksi antar pemikir hukum dengan 
Rizkiyah Hasanah, Penetapan Dispensasi Kawin Akibat Hamil Pra-Nikah Ditinjau Dari Aspek ....

lingkungan sosio-kultural atau sosiopolitik yang mengitarinya. Produk hukum semacam itu bisa diterima sebagai hukum positif dan bagian dari pengembangan hukum yang bersifat ijtihadiyah (Mu'allim, Amir dan Yusdani, 1999:131). Sistem adopsi ini juga didukung kaidah ushul fiqh yang mengatakan: "adat kebiasaan itu bisa menjadi hukum" (Nasrun Haroen, 1997:142), adapun perspektif psikologisnya penetapan hakim tersebut ditujukan untuk melakukan upaya preventif guna mencegah terjadinya problem lanjut dan sudah barang tentu akan menimbulkan persoalan baru bagi upaya pembangunan kesehatan bangsa yang meliputi kesehatan jasmani dan kesehatan mental bangsa.

\section{Analisis Penetapan Dispensasi} Kawin Akibat Hamil PraNikah Di Pengadilan Agama Banyuwangi Ditinjau Dari Aspek Maqashid Syari'ah Islam

Dalam kurun waktu enam tahun antara tahun 2008 sampai tahun 2013 sebanyak $99 \%$ perkara dispensasi kawin yang masuk telah dikabulkan dan diberikan penetapan dispensasi kawin oleh Hakim di Pengadilan Agama Banyuwangi. Penetapan hakim dalam memberikan dispensasi kawin akibat hamil pra-nikah di Pengadilan Agama Banyuwangi ditinjau dari aspek Maqashid Syari'ah Islam kiranya dapat penulis paparkan sebagai berikut:

Maqashid Syari'ah adalah tujuan hukum yang diturunkan Allah SWT. Menurut Al-Syatibi, hukumhukum disyari'atkan bertujuan untuk kemaslahatan umat manusia (Abu Ishaq Al-Syatibi, Tt:21). Menurut para ahli ushul fiqh ada lima unsur pokok yang harus dipelihara dan diwujudkan yaitu pemeliharaan agama (hifzh al-din), pemeliharaan jiwa (hifzh al-nafs), pemeliharaan akal (hifzh al-aql), pemeliharaan keturunan (hifzh al-nasl), dan pemeliharaan harta (hifzh al-mal) (Fathurrahman Djamil, 1999:125).

Terkait dengan penetapan hukum, maka kelima unsur pokok di atas dibedakan menjadi tiga peringkat: dharuriyyat, hajiyyat dan tahsiniyyat (Fathurrahman Djamil, 1999:126). 
Rizkiyah Hasanah, Penetapan Dispensasi Kawin Akibat Hamil Pra-Nikah Ditinjau Dari Aspek ....

Dharuriyyat adalah kebutuhan yang bersifat esensial bagi kehidupan manusia (primer), yang meliputi kebutuhan memelihara agama, jiwa, akal, keturunan dan harta. Apabila tidak terpenuhi atau tidak terpelihara kebutuhan-kebutuhan itu akan berakibat terancamnya eksistensi kelima pokok tersebut (Abu Ishaq Al-Syatibi, Tt:4). Peringkat hajjiyyat bisa diartikan sebagai kebutuhan yang dilakukan untuk memudahkan kelompok dharuriyyat. Sedangkan Peringkat tahsiniyyat dalam istilah yang mudah dipahami adalah kebutuhan pelengkap (tersier). Aplikasi dari tingkatan tahsiniyyat ini bisa diurutkan melalui aplikasi tingkatan dharuriyyat dan hajjiyyat. Pada tingkat dharuriyyat adalah berupa ibadah, tingkat hajjiyyat penyediaan terhadap sarana dan prasarana penunjang pelaksanaan ibadah, dan tingkat tahsiniyyat dalam melindungi agama adalah dengan menentukan bentuk bangunan masjid/mushalla tersebut.

Keberadaan agama, jiwa, akal, keturunan dan harta yang disebut sebagai lima unsur pokok, kemudian dikaitkan dengan kelompok peringkat dharuriyyat, hajjiyyat dan tahsiniyyat akan dijadikan analisis terhadap penetapan dispensasi kawin akibat hamil pra-nikah di Pengadilan Agama Banyuwangi.

a. Pemeliharaan agama (hifzh al-din) Dengan dibolehkan melangsungkan perkawinan bagi pasangan zina yang salah satu atau kedua-duanya masih di bawah umur menurut perundangan yang berlaku, meskipun dilakukan atas dasar keterpaksaan, hal itu sudah menunjukkan bukti melakukan taubat, dengan demikian pasangan tersebut berhenti melakukan perzinaan.

b. Pemeliharaan jiwa (hifzh al-nafs) Penetapan hakim yang membolehkan dilangsungkan perkawinan akibat hamil pra-nikah bagi pasangan yang masih berusia muda mempunyai makna penting bagi upaya pemeliharaan terhadap jiwa, sehingga dengan bantuan pasangan hidupnya mempelai wanita dapat memenuhi kebutuhan hidup seharihari untuk dirinya serta anaknya.

c. Pemeliharaan akal (hifzh al-`aql)

Seorang wanita hamil di luar nikah sangat rentan mengalami tekanan psikologis yang dapat 
Rizkiyah Hasanah, Penetapan Dispensasi Kawin Akibat Hamil Pra-Nikah Ditinjau Dari Aspek ....

berpengaruh terhadap kesehatan akal, terutama bagi pihak wanita. Beberapa dampak psikologis yang bisa ditimbulkan oleh wanita yang hamil di luar nikah antara lain : Turunnya kepercayaan diri, depresi dan ingin bunuh diri, melakukan tindak aborsi.

d. Pemeliharaan keturunan (hifzh alnasl)

Larangan zina dan melangsungkan perkawinan bagi pasangan zina yang masih berusia muda merupakan langkah dharuriyyah sebagai ranah primer dan langkah konkrit yang harus dilaksanakan dalam rangka untuk memberinya kejelasan status hukum sekaligus menjaga kelangsungan hidup anak hasil zina, agar kelak setelah lahir dapat melangsungkan kehidupannya secara normal dan tidak kehilangan haknya sebagai manusia secara individu maupun sebagai anggota masyarakat.

\section{e. Pemeliharaan harta (hifzh al-mal) Dengan dilangsungkan} perkawinan, akan berimplikasi pada terpeliharanya harta, berupa penggunaan dan pendistribusian harta sebagaimana mestinya, termasuk juga hak waris anak jika suatu saat orang tuanya meninggal bagi anak hasil zina, karena secara hukum telah dinyatakan jelas sebagai keturunan dari pemilik harta yang bersangkutan.

Dari analisis diatas, ditemukan kontradiksi yaitu di satu sisi belum terpenuhinya pemeliharaan terhadap agama (hifzh al-din) secara optimal dan pemeliharaan agama, jiwa, akal, harta tidak ditempatkan pada tingkatan dharuriyyat sebagai ranah primer yang harus dipelihara, sebaliknya di sisi lain penetapan hakim justru menempatkan unsur hifzh al-nasl dalam tingkat dharuriyyat untuk segera dilakukan pemeliharaan dengan tujuan menarik kemaslahatan yang lain. Hakim Pengadilan Agama Banyuwangi menggunakan kaidah ushuliyah yang berbunyi:

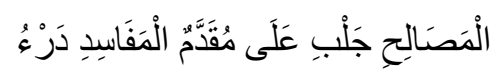

Artinya: "Menolak segala yang merusak harus didahulukan atas menarik segala yang bermaslahat".

Pasal 53 KHI merupakan bentuk dari ijtihad yang dilakukan oleh para ulama. Pada kenyataannya hasil ijtihad tersebut masih terkandung "madlarat" berupa 
Rizkiyah Hasanah, Penetapan Dispensasi Kawin Akibat Hamil Pra-Nikah Ditinjau Dari Aspek ....

peluang adanya praktek perzinaan yang semakin luas yang dilakukan oleh umat Islam Indonesia. Kehadiran Pasal 53 KHI sama saja membuka suatu jalan "legalitas" perzinaan sebagai imbas dari adanya pemberian dispensasi kawin akibat hamil pranikah.

Di sisi lain, keberadaan pengembangan hukum dalam Islam (ijtihad) tidak lain adalah bertujuan untuk menghilangkan madlarat yang akan atau bahkan telah mengancam kehidupan umat Islam. Salah satu kaidah yang sangat menjaga kemashlahatan umat Islam adalah kaidah saddu al-dzari'at. Pengertian saddu dzari'at menurut para ulama': "Mencegah sarana-sarana yang dapat menjadi sarana kepada keharaman, atau menyumbat jalan yang menyampaikan seseorang kepada kerusakan dan menolaknya"

(Syihabuddin Al-Qarafi, 232).

Ditinjau dari segi maslahat dan mafsadat, Penetapan Dispensasi Kawin akibat Hamil Pra-Nikah oleh Hakim Pengadilan Agama Banyuwangi dapat dianalisa sebagai berikut:

a. Sudut pandang maslahat
1) Perlindungan terhadap hak nasab anak.

Pasal 53 KHI dapat menjadi sarana bagi anak yang berada dalam kandungan untuk mendapatkan hak nasab ayahnya.

2) Perlindungan terhadap kehormatan.

Wanita hamil pra-nikah yang tidak segera dikawinkan dengan orang yang menghamilinya akan berdampak pada hilangnya kehormatan diri dan keluarganya.

b. Sudut pandang mafsadat.

Perbuatan zina merupakan salah satu perbuatan yang sangat dilarang oleh Allah. Larangan Allah mengenai zina dapat diketemukan dalam Al-Qur'an Surat Al Isra' ayat 32, yaitu sebagai berikut:

"Janganlah kamu mendekati zina, sesungguhnya zina itu adalah suatu perbuatan yang keji dan seburukburuknya jalan".

Selain larangan zina, Allah juga memberikan penjelasan mengenai ketentuan bagi para pezina. Berikut ini adalah dalil yang berhubungan dengan hukuman bagi pezina:

1) Perempuan yang berzina dan laki-laki yang berzina maka 
Rizkiyah Hasanah, Penetapan Dispensasi Kawin Akibat Hamil Pra-Nikah Ditinjau Dari Aspek ....

deralah tiap-tiap seorang dari keduanya seratus kali dera, dan janganlah betas kasihan kepada keduanya mencegah kamu untuk (menjalankan) agama Allah, jika kamu beriman kepada Allah dan hari akhirat, dan hendaklah (pelaksanaan) hukuman mereka disaksikan oleh sekumpulan dari orangorang yang beriman.

2) "Telah mengabarkan kepada kami dari Bisri bin Umar Zahroniy dari Hammad bin Salamah dari Qatadah dari alHasan dari Khittan bin Abdullah dari Ubadah bin AshShamit, sesungguhnya Rasulullah saw bersabda Allah telah memberikan jalan keluar bagi mereka (pezina), jejaka dengan gadis, hukumannya dera seratus kali dan pengasingan selama satu tahun. Sedangkan duda dengan janda, hukumannya dera seratus kali dan rajam" (HR. At-Tirmidzi).

\section{Keberadaan Pasal 53 KHI yang} tidak mencantumkan penyebab kehamilan dan sanksi akan memberikan dampak negatif berupa anggapan sebagai kebiasaan kehamilan akibat zina yang disengaja diluar nikah. Fenomena ini tentu akan menjadi permasalahan tersendiri bagi keberlangsungan pelaksanaan hukum Islam bagi umat Islam Indonesia

\section{(Abtadiussholikhin, 56).}

Keberadaan hukum berfungsi untuk menghilangkan kesempitan dalam kehidupan manusia, namun hal ini tidak dapat dilakukan tanpa adanya suatu syarat penyebab. Dalam Islam, hal ini disebut dengan aspek sabab (penyebab). Sabab terbagi ke dalam dua jenis, yakni penyebab yang di luar batas kemampuan manusia seperti penyebab berubahnya waktu siang menjadi malam dan penyebab yang berada dalam batas kemampuan manusia. Penyebab yang berada dalam batas manusia terbagi lagi menjadi dua pandangan yakni dalam pandangan hukum taklifi dan pandangan hukum wad'i (Amir Syarifuddin, 1997:331).

Terkait dengan zina, jelas sekali bahwa dalam hukum taklifi telah ada ketentuan yang mengaturnya. Meskipun hukumannya dipandang kurang relevan dengan keadaan masyarakat Indonesia, namun hal ini tidak lantas menjadikan hilangnya aspek sanksi bagi wanita hamil akibat zina. Sebab, tanpa adanya sanksi tersebut dikhawatirkan fungsi hukum sebagai sarana pencegahan suatu pelanggaran tidak akan dapat terlaksana (Abtadiussholikhin, 57). 
Kekhawatiran tersebut bukan tanpa sebab, faktanya kebanyakan perkara permohonan dispensasi kawin yang masuk di Pengadilan Agama Banyuwangi antara tahun 2008-2013 akibat hamil pra-nikah, tahun 2008: 14\% perkara, tahun 2009: $23 \%$ perkara, tahun 2010: $49 \%$ perkara, tahun 2011: 53\% perkara, tahun 2012: 47\% perkara dan tahun 2013: $36 \%$ perkara.

Penetapan dispensasi kawin akibat hamil pra-nikah ditinjau dari aspek maqashid syari'ah dari segi maslahatnya sebagai sarana untuk melindungi hak-hak manusia lebih mengutamakan pemeliharaan keturunan dan nasab anak (hifzh alnasl), sedangkan dari segi mafsadatnya pemeliharaan agama (hifz al-din) tidak tercapai, telah terjadi pelanggaran syari'at Islam yang menjadikan KHI Pasal 53 sebagai legalitas kawin hamil akibat zina. Untuk menghilangkan aspek mafsadat dalam Pasal 53 KHI dalam konteks saddu al-dzari'at diperlukan perubahan redaksi berupa penambahan ketentuan batasan penyebab kehamilan dan sanksi yang menyertainya.

\section{SIMPULAN}

1. Dasar hukum pertimbangan Majelis Hakim Pengadilan Agama Banyuwangi dalam menetapkan dispensasi kawin akibat hamil pra-nikah adalah:

a. Pertimbangan yuridis.

b. Pertimbangan hukum Islam.

c. Pertimbangan keadilan masyarakat.

2. Penetapan Dispensasi Kawin akibat hamil pra-nikah di Pengadilan Agama Banyuwangi ditinjau dari aspek maqashid syari'ah dari segi kemaslahatannya yaitu lebih mengutamakan pada aspek pemeliharaan keturunan dan nasab anak (hifzh al-nasl), sedangkan dari segi mafsadatnya yaitu pemeliharaan agama tidak tercapai (hifzh al-din), telah terjadi pelanggaran syari'at Islam tentang larangan zina.

\section{SARAN}

1. Hakim Pengadilan Agama harus selektif dan lebih cermat dalam menetapkan permohonan dispensasi kawin, Penetapan 
Rizkiyah Hasanah, Penetapan Dispensasi Kawin Akibat Hamil Pra-Nikah Ditinjau Dari Aspek ....

Dispensasi Kawin akibat hamil pra-nikah seyogyanya merupakan penetapan yang bersifat darurat.

2. Pasal 53 KHI dengan redaksi yang masih bersifat umum, mempunyai celah untuk dimanfaatkan sebagai legalisasi perzinaan. Oleh karena itu Peran aktif pemerintah, hakim, MUD, ormas Islam, muballigh, lembaga pendidikan, orang tua, dan masyarakat sangat dibutuhkan untuk bersifat kritis, inovatif dan kreatif dalam perkembangan hukum di masyarakat serta berupaya meminimalisir pergaulan bebas di kalangan remaja yang mengakibatkan kehamilan di luar nikah.

\section{DAFTAR PUSTAKA}

Al-'Arabi, Abu Bakar Muhammad bin Abdullah, Ahkamul Qur'an, Dar al-Fikr, Beirut, tt.

Al-Bukhari, Sahih al-Bukhari, 12/284, Maktabah asySyamilah.
Al-Syatibi, Abu Ishaq, al-Muwafaqat fi Ushul al-Ahkam, II.

Al-Syatibi, Abu Ishaq, al-Muwafaqat fi Ushul al-Ahkam I, Dar alFikr, Beirut, tt.

Amir Syarifuddin, Ushul Fiqh, Jilid I, Logos Wacana Ilmu, Jakarta, 1997.

Asy-Syaukani, Imam Muhammad, Nailul Authar (terj. Adib Bisri Musthafa), Asy-Syifa', Semarang, 1994.

Fathurrahman Djamil, Filsafat Hukum Islam, Logos Wacana Ilmu, Jakarta, 1997.

, Filsafat Hukum Islam, Logos Wacana Ilmu, Jakarta, 1999.

Hilman Hadikusuman, Metode Pembuatan Kertas atau Skripsi Ilmu Hukum, Mandar Maju, Bandung, 1995.

Ibnu Qudamah al-Maqdisyi, alMughni, juz 14, Maktabah asy-Syamilah al-Ishdar atsTsani.

Mu'allim, Amir dan Yusdani, Konfigurasi Pemikiran Hukum Islam, UII Press, Yogyakarta, 1999.

Mujamma' Al Malik Fahd Li Thiba' Al Mushaf As Syarif Madinah Munawarah, $A l$ Qur'an Dan Terjemahnya, 1971. 
Rizkiyah Hasanah, Penetapan Dispensasi Kawin Akibat Hamil Pra-Nikah Ditinjau Dari Aspek ....

Mukhtar Yahya, Fatchurrahman, Dasar-dasar Pembinaan Hukum Fiqh Islami, $\mathrm{Al}$ Ma’arif, Bandung, 1993.

Nasrun Haroen, Ushul Fiqh, Logos Wacana Ilmu, Jakarta, 1997.

Qunduz Muhammad Al-Mahy, dalam Al-Qarafi, Syihabuddin, Qawai'idul Mashlahah wal Mafsadah Min Khilali Kitabihi Al-Furuq, Daru Ibni Hazmin.

Sayyid Sabiq, Fiqhussunnah, alih bahasa Muhammad Thalib, Cet, I, PT. A 1-Ma'arif, Bandung, 1980.

Zakiah Daradjat, Ilmu Figh, Jilid II, Dana Bhakti Wakaf, Yogyakarta, 1995.

Abtadiussholikhin, Analisis Kawin Hamil (Studi Pasal 53 KHI Dalam Perspektif Sadd AlDzari'ah, Fakultas Syari'ah IAIN Walisongo, Semarang, Skripsi.

Disarikan dari "Kontroversi Perkawinan Wanita Hamil", karya Mukhlisin Muzarie, Ro'is Aam Tanfidhiyyah DPP Jama'ah Rifa'iyyah.

Framework PTA Surabaya, Summary Perkara Masuk Se-Wilayah
PTA Surabaya, Siadpa \& SiadPTA Plus, 2008-2013.

Kebijakan Kesehatan Indonesia, BKKBN:Seks Bebas Kini Masalah Utama Remaja Indonesia, http://kebijakankesehatanind onesia.net/component/comte nt/article/73-berita/1233bkkbn-seks-bebas-kinimasalah-utama-remajaindonesia.html

$\underline{\text { adminbaitulhikmah.com }}$

Thursday, 11 February 2010, Bahsul Masa'il, Fikih. 